This is the final peer-reviewed accepted manuscript of:

M. Massaro, C. G. Colletti, R. Noto, S. Riela, P. Poma, S. Guernelli, F. Parisi, S. Milioto, G. Lazzara Pharmaceutical properties of supramolecular assembly of co-loaded cardanol/triazole-halloysite systems

INTERNATIONAL JOURNAL OF PHARMACEUTICS, (2015), vol. 478, p. 476-485

The final published version is available online at: http://dx.doi.org/10.1016/j.ijpharm.2014.12.004

Rights / License:

The terms and conditions for the reuse of this version of the manuscript are specified in the publishing policy. For all terms of use and more information see the publisher's website.

This item was downloaded from IRIS Università di Bologna (https://cris.unibo.it/)

When citing, please refer to the published version. 
Pharmaceutical nanotechnology

\title{
Pharmaceutical properties of supramolecular assembly of co-loaded cardanol/triazole-halloysite systems
}

\author{
Marina Massaro, Carmelo G. Colletti, Renato Noto, Serena Riela, Paola Poma, \\ Susanna Guernelli, Filippo Parisi, Stefana Milioto, Giuseppe Lazzara \\ a Dipartimento STEBICEF, sez. Chimica, Università di Palermo, Viale delle Scienze, Parco d'Orleans II, Ed. 17, 90128 Palermo, Italy \\ b Dipartimento di Scienze per la Promozione della Salute e Materno Infantile “G. D'Alessandro”, Area Funzionale di Farmacologia, Università di Palermo, Via \\ del Vespro 129, 90127 Palermo, Italy \\ 'Dipartimento di Chimica “G. Ciamician", Università di Bologna, via San Giacomo 11, 40126 Bologna, Italy \\ 'Dipartimento di Fisica e Chimica, Università di Palermo, Viale delle Scienze, Parco d'Orleans II, Ed. 17, 90128 Palermo, Italy
}

\begin{abstract}
A B S T R A C T
Halloysite nanotubes were explored as drug carrier for cardanol, which is considered as a promising natural anticancer active species. To this aim, besides the pristine nanoclay, a chemical modification of the nanocarrier was performed by attaching triazolium salts with different hydrophobicity at the outer surface of the hollow nanotubes. The interaction between cardanol and nanotubes was highlighted in solution by HPLC. This method proved the loading of the drug into the nanotubes. The solid dried complexes formed by pristine and modified halloysite with the cardanol were characterized by IR spectroscopy, thermogravimetric analysis as well as water contact angle to evidence the structure, thermal properties and wettability of the obtained materials. The kinetics of cardanol release as well as cell viability experiments provided promising results that put forward a new strategy for potential applications of cardanol as active antiproliferative molecule and clay nanotubes as drug carrier.
\end{abstract}

(c) 2014 Published by Elsevier B.V.

\section{Introduction}

Liver cancer is a major malignant tumor worldwide and is the third most common cause of cancer-related mortality (Feng et al., 2013). Over $80 \%$ of liver cancer patients are diagnosed with hepatocellular carcinoma, which is resistant to most conventional chemotherapeutic agents (Wilson et al., 2012). Moreover, the use of chemoprevention agents is typically associated with side effects that lead to the destruction of normal tissues, such as those of the digestive, hematopoietic and nervous systems (Meyskens and Gerner, 1999; Suzuki et al., 2008; Florea and Büsselberg, 2011). The development of drugs that specifically target tumor cells, but not normal cells, represents a common goal. Natural compounds contain various types of medicinal ingredients, including vitamin derivatives, phenolic and flavonoid agents, organic sulfur compounds, isothiocyanates, curcumins, fatty acids and D-limonene (Amin et al., 2009; Gullett et al., 2010; Tsuda et al., 2004), and sufficient evidences have demonstrated that these components can substantially inhibit tumor formation (Amin et al., 2009).

Cardanol is one of the promising renewable natural resources, obtained as the main fraction from the distillation of cashew nut shell liquid (Fig. 1). The presence of a C15-long aliphatic chain attached to the meta position of the phenolic ring confers exclusive properties to cardanol derivatives, such as high solubility in nonpolar environments and good processability.

Current studies about the antiproliferative/cytotoxic activity on cancer cell lines of extracts of Thai Apis mellifera propolis containing cardanol and cardol as main bioactive components have established potential anticancer bioactivity (Teerasripreecha et al., 2012).

However a crucial drawback in the use of natural compounds as drug candidates is their very low solubility in physiological media; therefore, a number of drug carriers have been developed to overcome this problem.

In the last year the use of porous materials as carriers for the encapsulation and delivery of drugs has received considerable attention because of their stable structure and controllable surface 


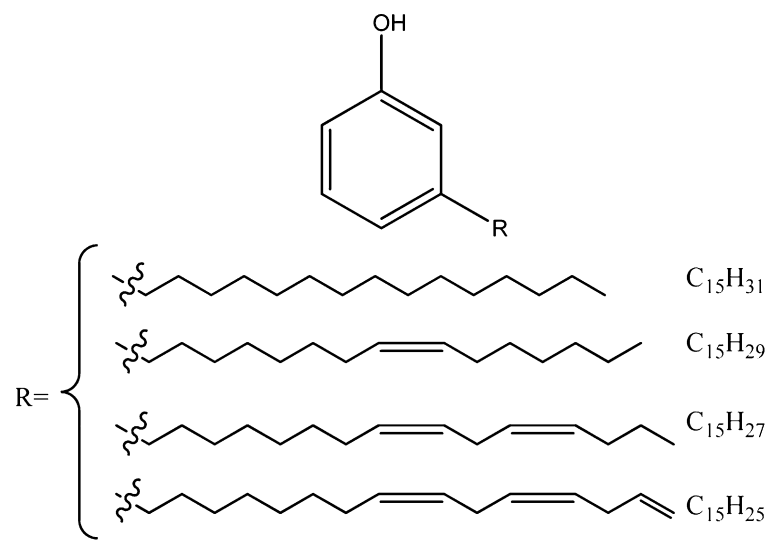

Fig. 1. Molecular structure and composition of cardanol.

reactivity (Horcajada et al., 2006; Ito et al., 2005; Jain et al., 2005; Martucci et al., 2012; Mizushima et al., 2006; Song et al., 2005; Streubel et al., 2002; Vallet-Regi et al., 2001).

Among the materials that have porous structure, halloysite (HNT), a natural aluminosilicate clay with a hollow tubular structure, is enable to load and to release biomacromolecules and drugs (Joussein et al., 2005; Price et al., 2001; Shchukin et al., 2005).

Intracellular uptake by cells of different origins (cervical adenocarcinoma or breast cancer cells) and cytoviability tests demonstrated relative halloysite cytocompatibility and potential as a bio-friendly cargo nanocontainer for biomaterials (Vergaro et al., 2010).

Modification of the halloysite tube outer surface via covalent bond formation may open up new applications based upon molecular recognition, such as molecular separation, molecular storage, catalysis, and drug delivery (Abdullayev and Lvov, 2010; Abdullayev et al., 2011; Lvov et al., 2008; Massaro et al., 2014a,b,c).

In our previous research we demonstrated that modified HNT with triazolium salts (f-HNT) (Fig. 2) improves the antitumor effect of curcumin in physiological medium when compared with the use of curcumin alone. It is interesting to note that the presence of the biological active triazolium moiety exerts a synergic effect with curcumin that carry out in an increased cytotoxic activity of the new nano-formulation, HNT-triazolium salts/Curcumin, against several tumor cell lines (Riela et al., 2014).

In this work, for the first time, reverse-phase HPLC technique was used to analyze if the halloysite nanotubes could be a suitable carrier for drug molecules. HPLC equipped with Diode-Array/UV detector offers the remarkable advantage to record in real time the UV-vis spectrum of the chromatographic eluate (in the range $200-600 \mathrm{~nm}$ ), and therefore it allows the simultaneous monitoring of different species/analytes.

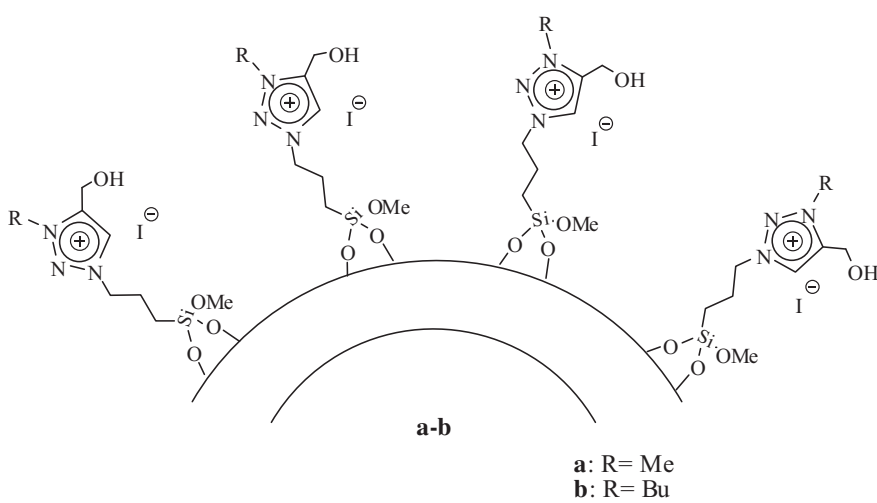

Fig. 2. Schematic representation of functionalized triazolium salt HNT (f-HNT).
We report a study of the supramolecular interaction between pristine halloysite (p-HNT) and cardanol by thermogravimetric analysis (TGA), IR spectroscopy, dynamic light scattering (DLS), contact angles measurements and SEM investigations. Moreover, the effect of the surface functionalization of halloysite with triazolium salts (f-HNT), the synergic effect, on the loading of cardanol was also investigated. Finally the cytotoxic effect on three different hepatocarcinoma cell lines, HA22T/VGH, Hep3B and HepG2, was evaluated, too.

\section{Experimentals}

All reagents needed were used as purchased (Aldrich), without further purification.

Cardanol was provided by Prof. Attanasi, University of Urbino.

Halloysite was supplied by Applied Minerals. This material has an average tube diameter of $50 \mathrm{~nm}$ and inner lumen diameter of $15 \mathrm{~nm}$. Typical specific surface area of this halloysite is $65 \mathrm{~m}^{2} / \mathrm{g}$; pore volume of $\sim 1.25 \mathrm{~mL} / \mathrm{g}$; refractive index 1.54; and specific gravity $2.53 \mathrm{~g} / \mathrm{cm}^{3}$.

Functionalized triazolium salt halloysite was prepared as previously reported (Riela et al., 2014).

The UV-vis absorbance spectra were recorded with a Beckmann DU 650 spectrometer.

The microscope ESEM FEI QUANTA 200F was used to study the morphology of the functionalized HNTs. Before each experiment, the sample was coated with gold in argon by means of an Edwards Sputter Coater S150A to avoid charging under electron beam.

Thermogravimetric analyses were performed by a Q5000 IR apparatus (TA Instruments) under a nitrogen flow of $25 \mathrm{~cm}^{3} \mathrm{~min}^{-1}$ for the sample and $10 \mathrm{~cm}^{3} \mathrm{~min}^{-1}$ for the balance. The weight of each sample was ca. $10 \mathrm{mg}$. The measurements were carried out by heating the sample from room temperature to $900{ }^{\circ} \mathrm{C}$ at a rate of $10{ }^{\circ} \mathrm{Cmin}^{-1}$.

The DLS measurements were performed at $22.0 \pm 0.1^{\circ} \mathrm{C}$ in a sealed cylindrical scattering cell at a scattering angle of $90^{\circ}$ by means of a Brookhaven Instrument apparatus composed of an BI9000ATcorrelator and a He-Ne laser $(75 \mathrm{~mW})$ with a wavelength $(\lambda)$ of $632.8 \mathrm{~nm}$. The solvent was filtered by means of a Millipore filter with $0.45 \mu \mathrm{m}$ pore size. For all systems, the field-time autocorrelation functions were well described by a monoexponential decay function, which provides the decay rate $(\Gamma)$ of the single diffusive mode. For the translational motion, the collective diffusion coefficient at a given concentration is $D_{\mathrm{t}}=\Gamma / q^{2}$ where $q$ is the scattering vector given by $4 \pi R_{\mathrm{I}} \lambda^{-1} \sin (\theta / 2)$ being $R_{\mathrm{I}}$ the water refractive index and $\theta$ the scattering angle.

Contact angle measurements were performed by using an optical contact angle apparatus (OCA 20, Data Physics Instruments) equipped with a video measuring system having a high-resolution CCD camera and a high-performance digitizing adapter. SCA 20 software (Data Physics Instruments) was used for data acquisition. To obtain a tablet, the powder like material was pressed under $10^{4} \mathrm{~kg} \mathrm{~cm}^{-2}$ for $10 \mathrm{~min}$. The contact angle of water in air was measured by the sessile drop method. The water droplet volume was $10.0 \pm 0.5 \mu \mathrm{L}$. Temperature was set at $25.0 \pm 0.1^{\circ} \mathrm{C}$ for the support and the injecting syringe as well. Images were collected 25 times per second. From the data analysis the contact angle, the volume and the contact area of the drop were calculated. The volume of the droplet was constant within the time of the experiment.

The dispersions were sonicated with an ultrasound bath VWR Ultrasonic Cleaner (power $200 \mathrm{~W}$, frequency $75 \mathrm{MHz}$ ).

The chromatographic measurements were performed using a Shimadzu Class VP (Shimadzu, Japan) which consist of a pump (LC-10AD VP Shimadzu), an injection valve equipped with a $20 \mu \mathrm{L}$ injection loop, an UV-vis Diode-Array (SPD-M10A VP) detector and an acquisition data software Class-VP. After optimization of 
chromatographic conditions, separation was carried out on $\mathrm{C}_{18}$ column (Discovery Supelco, $25 \mathrm{~cm} \times 4.6 \mathrm{~mm}, 5 \mu \mathrm{m}$ ). The mobile phase consisted of methanol/water, at room temperature, in different ratio $\mathrm{v} / \mathrm{v}$ and flow as reported afterwards. Chromatograms were analyzed at 210, 240 and $269 \mathrm{~nm}$ according to the cases investigated.

The dispersions were sonicated with an ultrasound bath VWR Ultrasonic Cleaner (power $200 \mathrm{~W}$, frequency $75 \mathrm{MHz}$ ).

\subsection{General procedure for preparation of dispersions HNT/cardanol}

Varying weighted amounts of p-HNT or f-HNT (between 2 and $16 \mathrm{mg}$ ) were dispersed, for $5 \mathrm{~min}$, by sonication in $\mathrm{H}_{2} \mathrm{O} / \mathrm{MeOH}$ 9:1 mixture at an ultrasound power of $200 \mathrm{~W}$ and a temperature of $25^{\circ} \mathrm{C}$. A solution in the same mixture $(1 \mathrm{~mL})$ of cardanol $\left(1 \times 10^{-3} \mathrm{M}\right)$ was added to the HNT dispersions. The final volume was $10 \mathrm{~mL}$.

\subsection{Loading procedure}

\subsubsection{Pristine HNT}

In order to encapsulate cardanol inside halloysite nanotubes, we have mixed $20 \mathrm{mg}$ of halloysite, as dry powder, with $1 \mathrm{~mL}$ of saturated solution of cardanol in methanol. The suspension was sonicated for $5 \mathrm{~min}$, at an ultrasound power of $200 \mathrm{~W}$ and a temperature of $25^{\circ} \mathrm{C}$ and then was evacuated overnight. The powder was washed with $\mathrm{H}_{2} \mathrm{O}$ and then dried at $80^{\circ} \mathrm{C}$ under vacuum.

\subsection{2. f-HNT}

To a dispersion of $\mathrm{f}-\mathrm{HNT}$ in water/methanol 9:1 $(250 \mathrm{~mL})$ were added $2.5 \mathrm{~mL}$ of a cardanol solution $10^{-2} \mathrm{M}$ in methanol. The obtained dispersion was stirred for $48 \mathrm{~h}$ at r.t. and then was filtered, the powder was washed with small amounts of $\mathrm{H}_{2} \mathrm{O}$ and then dried at $60^{\circ} \mathrm{C}$ under vacuum overnight.

\subsection{In vitro drug release}

The release of cardanol from the f-HNT/Card complexes was done as following: $25 \mathrm{mg}$ of the sample were dispersed in $1 \mathrm{~mL}$ of dissolution medium and transferred into a dialysis membrane (Medicell International Ltd MWCO 12-14000 with diameter of $21.5 \mathrm{~mm}$ ). Subsequently the membrane was put in a round bottom flask containing $10 \mathrm{~mL}$ of the release medium at $37^{\circ} \mathrm{C}$ and stirred.

Three different media $(0.1 \mathrm{M} \mathrm{HCl}$, phosphate buffer $\mathrm{pH} 6$ and 7.4, respectively) were considered in order to evaluate the influence of $\mathrm{pH}$ on the release behavior of the drug.

At fixed time, $1 \mathrm{~mL}$ of the release medium has been withdrawn and analyzed by UV-vis. To keep constant the volume of the release medium $1 \mathrm{~mL}$ of fresh solution $(0.1 \mathrm{M} \mathrm{HCl}, \mathrm{pH} 6$ buffer or 7.4 buffer) has been used to replace the collected one.

The cardanol concentration in the solution was determined by UV-vis spectrophotometry using the Lambert-Beer law.

Total amounts of drug released $\left(F_{t}\right)$ were calculated as follows:

$F_{t}=V_{\mathrm{m}} C_{t}+\sum_{i=0}^{t-1} V_{\mathrm{a}} C_{i}$

where $V_{\mathrm{m}}$ and $C_{t}$ are volume and concentration of the drug at time $t$. $V_{\mathrm{a}}$ is the volume of the sample withdrawn and $C_{i}$ is drug concentration at time $i(i<t)$.

\subsection{Cell culture}

HA22T/VGH, HepG2 and Hep3B are a poorly differentiated hepatoma cell lines which contain HBV integrants. It was cultured in Roswell Park Memorial Institute (RPMI) 1640 (HyClone Europe Ltd., Cramlington, UK) supplemented with $10 \%$ heat-inactivated fetal calf serum, $2 \mathrm{mM}$ L-glutamine, $1 \mathrm{mM}$ sodium pyruvate, 100 units $/ \mathrm{mL}$ penicillin and $100 \mathrm{mg} / \mathrm{mL}$ streptomycin (all reagents were from HyClone Europe) in a humidified atmosphere at $37^{\circ} \mathrm{C}$ in $5 \% \mathrm{CO}_{2}$. Cells having a narrow range of passage number were used for all experiments.

\subsection{Cell growth assays}

The cells were seeded at $2 \times 10^{4}$ cells/well onto 96 -well plates and then incubated overnight. At time 0 , medium was replaced with fresh complete medium and cardanol, f-HNT and f-HNT/Card thereof were added in concentrations as indicated. At the end of treatment, $16 \mu \mathrm{L}$ of a commercial solution (obtained from Promega Corporation, Madison, WI, USA) containing 3-(4,5-dimethylthiazol-2-yl)5-(3-carboxy methoxyphenyl)-2-(4-sulphophenyl)-2H-tetrazolium (MTS) and phenazine ethosulfate were added. The plates were incubated for $2 \mathrm{~h}$ in a humidified atmosphere at $37^{\circ} \mathrm{C}$ in $5 \% \mathrm{CO}_{2}$. The bioreduction of the MTS dye was assessed by measuring the absorbance of each well at $490 \mathrm{~nm}$. Cytotoxicity was expressed as a percentage of the absorbance measured in the control cells.

\section{Results and discussion}

\subsection{Characterization of complexes in solution}

Reverse-phase HPLC was used in order to investigate the supramolecular interaction between pristine or modified HNT and cardanol.
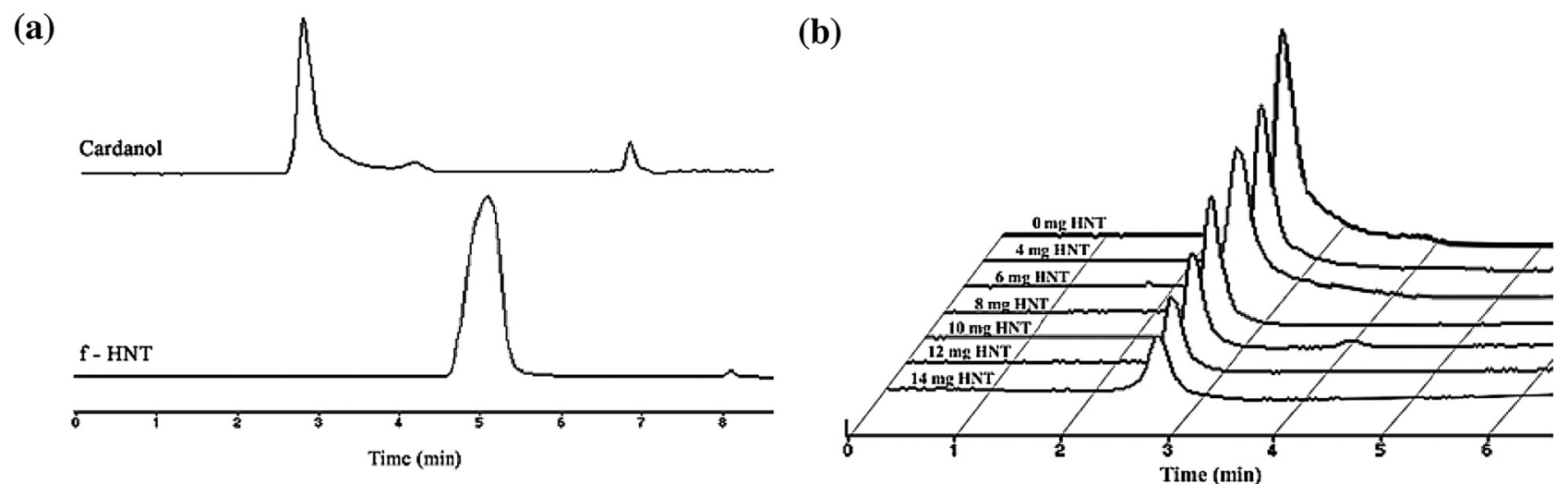

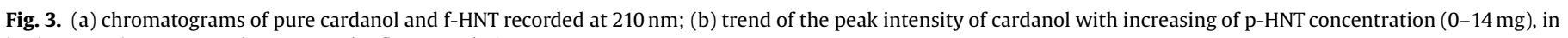
both cases eluent: $\mathrm{MeOH} / \mathrm{H}_{2} \mathrm{O} 98: 2 \mathrm{v} / \mathrm{v}$; flow $1 \mathrm{~mL} / \mathrm{min}$. 
(a)

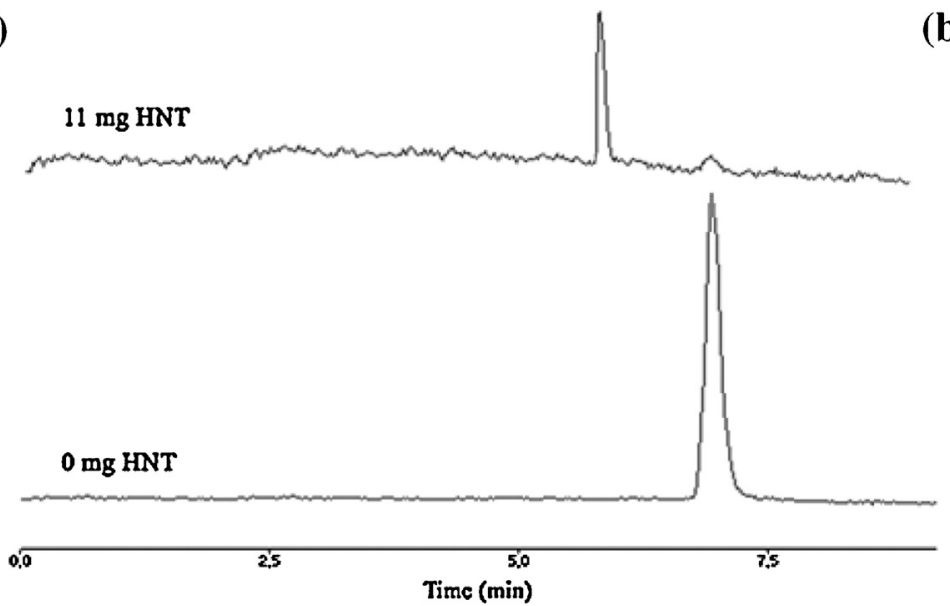

(b)

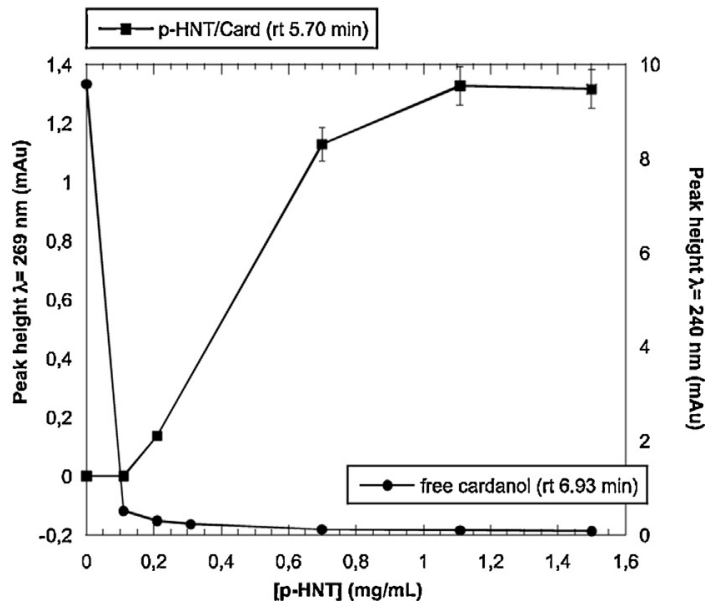

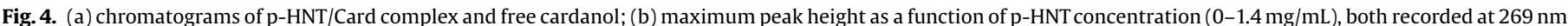
(eluent: $\mathrm{MeOH} / \mathrm{H}_{2} \mathrm{O} 90: 10 \mathrm{v} / \mathrm{v}$; flow $0.8 \mathrm{~mL} / \mathrm{min}$ ).

According to previous reports, pure cardanol (Mahata et al., 2014), showed three peaks in its HPLC chromatogram, corresponding to $3-[8(Z), 11(Z), 14-$ pentadecatrienyl] phenol $(79.20 \%)$, 3-[8(Z),11(Z)-pentadecadienyl] phenol (0.01\%) and 3-[8(Z)-pentadecadecenyl] phenol (20.79\%) with retention times (r.t.) of 2.84 , 4.21 and $7.70 \mathrm{~min}$ respectively, recorded at $210 \mathrm{~nm}$. The most abundant component displayed two bands in its UV spectrum, a first one at $210 \mathrm{~nm}$ and the second one, less intense, at $269 \mathrm{~nm} \mathrm{ca}$.

No peaks were observed in the chromatogram related to p-HNT, since this material shows no UV absorption. By the contrast, the f-HNT exhibits a peak at r.t. $5.45 \mathrm{~min}$ and a UV spectrum with an absorption band at $220 \mathrm{~nm}$, attributable to the triazole ring presents on the outer surface of the HNT tubes (Fig. 3a).

Fig. $3 \mathrm{~b}$, shows the titration of a fixed cardanol concentration $\left(1 \times 10^{-4} \mathrm{M}\right.$ ) with increasing amounts of $\mathrm{p}-\mathrm{HNT}$ (ranging from 0 to $14 \mathrm{mg}$ )

In Fig. $3 \mathrm{~b}$ in particular, all peaks in the reported chromatograms, monitored at $210 \mathrm{~nm}$, are related to the supernatant solution after deposition of a white solid. The chromatograms exhibit a decrease in the intensity of the cardanol peak (r.t. $2.84 \mathrm{~min}$ ), on increasing amounts of p-HNT. This finding suggests that the formation of HNT/Card complex occurs.

In order to identify the possible presence of p-HNT/Card complex we changed the experimental conditions by modifying eluent and reducing flow (eluent: $\mathrm{MeOH} / \mathrm{H}_{2} \mathrm{O}$ 90:10 v/v; flow
$0.8 \mathrm{~mL} / \mathrm{min}$ ) and we recorded chromatogram of the dispersions after sonication, monitored at $269 \mathrm{~nm}$ (Fig. 4).

The free cardanol showed a peak at r.t. of $6.93 \mathrm{~min}$, while on increasing of the amount of p-HNT a new peak appeared, at lower r.t. (5.70 min) with a concomitant hypsochromic shift of the absorption band of cardanol from 269 to $240 \mathrm{~nm}$ (Fig. 4a). This shift can be attributed to the formation of a complex between cardanol and p-HNT, where the biological molecule is adsorbed onto the HNT surface, in agreement with the TGA and SEM evidences discussed afterwards. The reduction of cardanol retention time may be explained considering that the absorption of cardanol onto the p-HNT surface causes a less extensive interaction between the stationary phase and the biological molecule.

A quantitative analysis of the HPLC results, endowing the evaluation of free and adsorbed cardanol, is shown in Fig. 4b. The amount of complex, recorded at $240 \mathrm{~nm}$, increases on increasing the p-HNT concentration approaching a plateau.

HPLC measurements resulted advantageous to highlight the strong interaction occurring in $\mathrm{f}-\mathrm{HNT} /$ Card supramolecular complexes. A different behavior was observed respect to p-HNT; indeed at f-HNT concentration larger than $0.4 \mathrm{mg} / \mathrm{mL}$, surprisingly, no free cardanol was detected.

Under the experimental conditions adopted (eluent: $\mathrm{MeOH} /$ $\mathrm{H}_{2} \mathrm{O} 98: 2 \mathrm{v} / \mathrm{v}$; flow $1 \mathrm{~mL} / \mathrm{min}$ ), the f-HNT/Card dispersion after sonication, displays a chromatogram (monitored at $\lambda=210 \mathrm{~nm}$ ) (a)

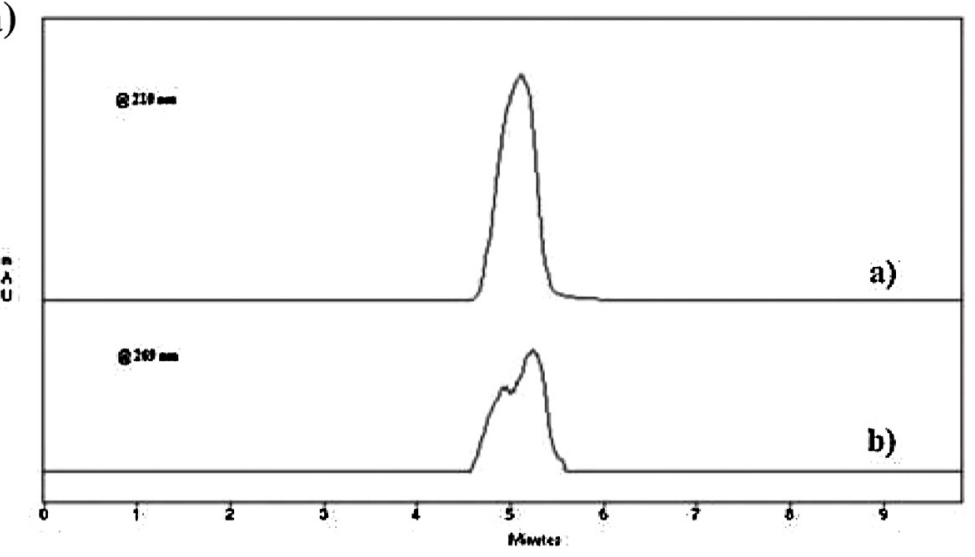

(b)

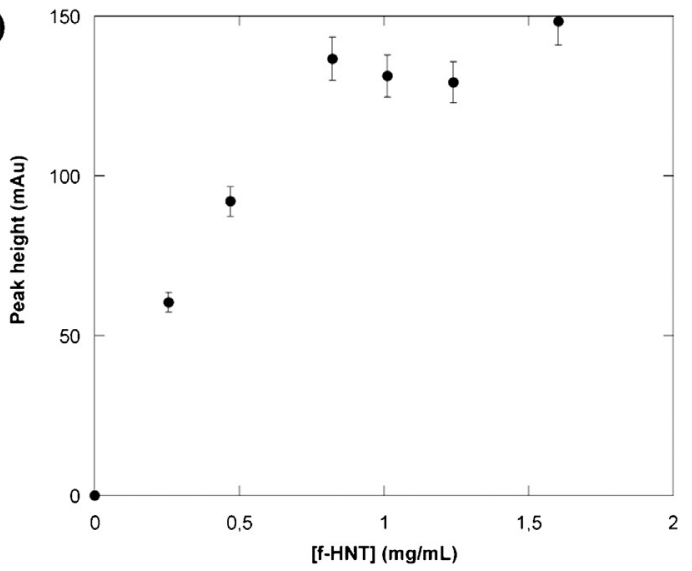

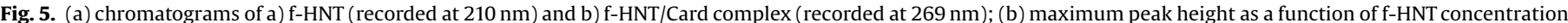
$\left(0-1.4 \mathrm{mg} / \mathrm{mL}\right.$ ) recorded at $269 \mathrm{~nm}$ (eluent: $\mathrm{MeOH} / \mathrm{H}_{2} \mathrm{O} 98: 2 \mathrm{v} / \mathrm{v}$; flow $1 \mathrm{~mL} / \mathrm{min}$ ). 
with a peak at a $5.11 \mathrm{~min}$ r.t.; on the other hand, in the chromatogram recorded at $269 \mathrm{~nm}$, two different peaks were observed at 4.94 and 5.23 min r.t.s., respectively. In particular, the UV spectrum of the peak at 5.23 min r.t. showed two absorption bands, the first at $220 \mathrm{~nm}$ and a second one, less intense at $269 \mathrm{~nm}$, typical of cardanol molecule (Fig. 5a), therefore, second peak could be the evidence of the complex f-HNT/Card.

The quantitative analysis of complex is shown in Fig. 4b. A very rapid increase in the intensity of the chromatographic peak is observed with small amount of f-HNT, less than $0.4 \mathrm{mg} / \mathrm{mL}$, then a plateau is reached. Therefore strong interaction occurs even at low f-HNT concentration. This fact could be due to the supramolecular aggregation between cardanol and triazole moiety by $\pi-\pi$ and van der Waals interactions and hydrogen bonding.

The stability of f-HNT dispersions in the presence of variable amounts of cardanol was investigated by dynamic light scattering. Within the experimental errors, the obtained diffusion coefficients are independent on concentration and therefore the average values of $4.2 \times 10^{-13}$ and $3.2 \times 10^{-13} \mathrm{~m} \mathrm{~s}^{-2}$ were calculated for $\mathrm{f}-\mathrm{HNTa}-\mathrm{b} /$ Card, respectively. These values are ca. half those expected considering the characteristic lengths of the nanotubes $\left(9.4 \times 10^{-13}\right.$ $\mathrm{ms}^{-2}$ ). Such a decrease can be ascribed to both a partial aggregation of nanotubes or a slowing down of the diffusion due to the adsorption of cardanol at the outer surface of f-HNT.

\subsection{Characterization of solid complexes}

The dried complexes of cardanol with p-HNT and f-HNT were investigated by thermogravimetric analysis. Fig. 6 shows the thermoanalytical curves of the complexes to which the curve for $\mathrm{p}$ HNT and f-HNT, respectively, were subtracted. This procedure allows us to evidence the cardanol presence even though several degradation processes are present in the composite materials. The obtained curves show a single mass loss step occuring in a temperature range (from $200^{\circ} \mathrm{C}$ to $260^{\circ} \mathrm{C}$ ) comparable to that measured for free cardanol (Fig. 6) and consistent with the compound evaporation (Izzo and Dawson, 1950). Given that the boiling point of cardanol in the composite is unaltered, we can hypothesize that it is adsorbed at the outer nanotubes surfaces. The amount of loaded cardanol determined from the mass loss differences are ca. $5 \mathrm{wt} \%$ and $10 \mathrm{wt} \%$ for p-HNT and f-HNT, respectively. Namely, the HNT functionalization doubled the cardanol loading efficiency regardles of the alkylic chain nature linked to the triazole moiety.

These findings agree with the HPLC results and take into account for the strong hydrophobic interactions between the outer surface of f-HNT and cardanol. Interestingly we observed a

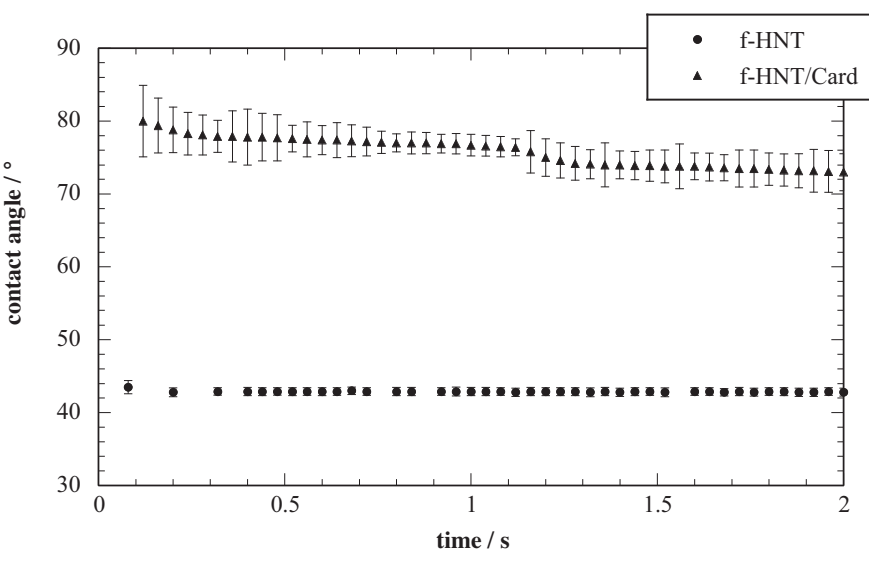

Fig. 7. Contact angle as a function of time for f-HNT and f-HNT/Card complex.

peculiar aging effect on the p-HNT/Card complex. In particular, the thermoanalytical curve profile for the material obtained after 20 days of stirring showed two well resolved mass loss steps at ca. $200^{\circ} \mathrm{C}$ and $350^{\circ} \mathrm{C}$ (Fig. 6a). The first step is consistent with the presence of adsorbed cardanol, while the second mass loss process can be related to cardanol strongly interacting with the p-HNT lumen or interlayers. Going further, based on geometrical consideration on the p-HNT size (Abdullayev et al., 2012), the loading amount of $10.2 \%$ estimated from the mass loss at $350^{\circ} \mathrm{C}$ indicates a complete filling of the p-HNT cavity. These results prove that the incorporation of cardanol is a very slow process. To highlight the cardanol site into the solid complexes, contact angle $(\theta)$ experiments were performed. In general, the $\theta$ value of water onto a solid substrate depends on both chemical composition and surface roughness. In our case, pellets were obtained by pressing the dry powder at $10^{4} \mathrm{~kg} \mathrm{~cm}^{-2}$ in order to ensure a smooth surface providing a $\theta$ value straightforwardly related to the surface composition and hydrophobicity. As Fig. 7 shows, $\theta$ is nearly constant within the experiment time and it is strongly altered by the presence of cardanol. These trends indicate that both water adsorption and spreading are negligible and therefore an average value of $\theta$ can be calculated from the data in Fig. 7 and in particular $42.5 \pm 0.3^{\circ}$ and $75 \pm 2^{\circ}$ is obtained for f-HNT and f-HNT/Card, respectively. The increase of $\theta$ value is consistent with the hydrophobic nature of cardanol and its adsorption at the outer surface of the nanotubes. Similar conclusion can be draw for p-HNT and p-HNT/Card complex.

The surface morphology of p-HNT/Card and f-HNT/Card complexes was imaged by SEM. It clearly appears that the tubular
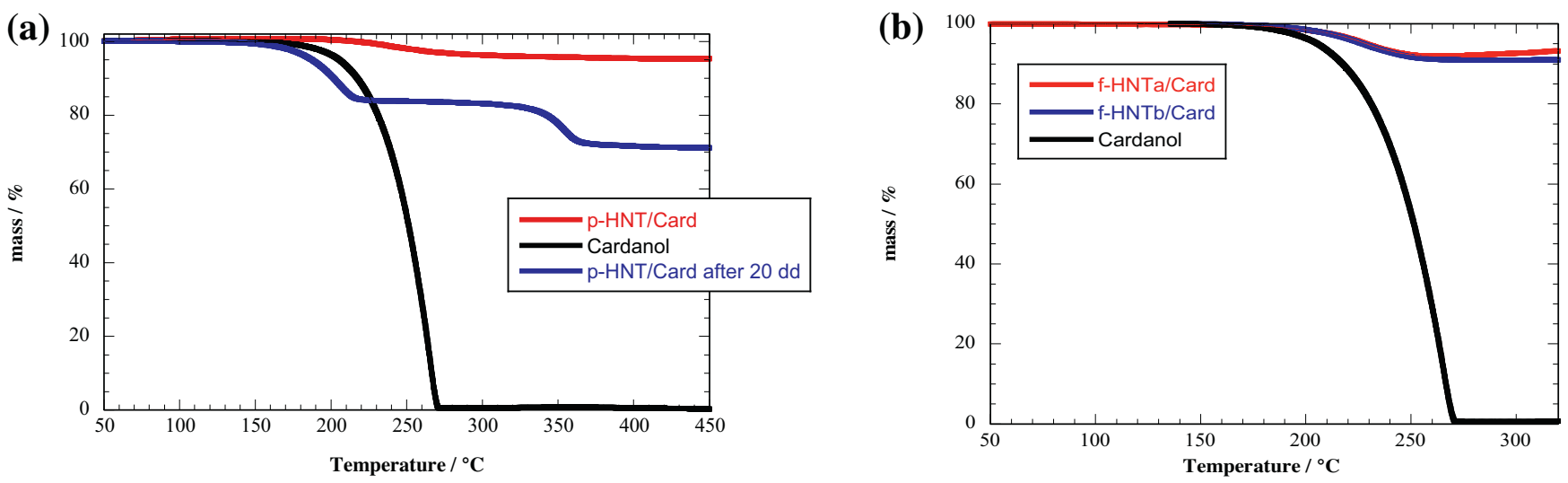

Fig. 6. Thermoanalytical curves of (a) p-HNT/Card complexes and (b) f-HNT/Card complexes in comparisono with free cardanol. 
shape of the halloysite is maintained after the surface modification and cardanol adsorption. A carefull look of the images evidenced the empty cavity of the nanoclay (Fig. 8a) with an average inner radius of $17 \mathrm{~nm}$ and a outer radius of $70 \mathrm{~nm}$. The presence of the hollow cavities and the smooth outer surface of the nanotubes confirms that the cardanol adsorption occurs at the external surface (Fig. $8 \mathrm{~b}$ and $\mathrm{c}$ ).

Finally, FT-IR spectra of cardanol, f-HNT and f-HNT/Card complex were recorded at room temperature in a spectral region between 4000 and $400 \mathrm{~cm}^{-1}$ to further confirm interaction of cardanol with outer surface of HNT (Fig. 9).

f-HNT spectrum (Curve $b$ ) exhibits, in addition to the characteristic stretching bands of pristine halloysite (Yuang et al., 2008), the stretching bands of triazolium moiety as we have previously reported (Riela et al., 2014).

In the spectrum of pure cardanol (Curve $c$ ), the broad band at ca. $3300 \mathrm{~cm}^{-1}$ is attributed to $-\mathrm{OH}$ stretching vibration, the bands at 2957, 2917 and $2850 \mathrm{~cm}^{-1}$ correspond to asymmetric and symmetric stretching of the methyl and methylene groups and the bands between 1587 and $900 \mathrm{~cm}^{-1}$ derive from stretching and bending of aromatic ring and $\mathrm{C}-\mathrm{O}$ stretching vibration. All these characteristic bands are present in the spectrum of $\mathrm{f}-\mathrm{HNT} / \mathrm{Card}$ (Curve $a$ ), which provides direct evidence for the successful loading of cardanol on f-HNT surface.

Based on the unaltered frequency of stretching bands of the $\mathrm{OH}$ of the inner-surface $\mathrm{Al}-\mathrm{OH}$ groups, and stretching bands of cardanol, led to conclude that cardanol has been adsorbed only on the external surface of f-HNT.

\subsection{Kinetic release}

In Fig. 10 extended release profile of cardanol from f-HNT, in three different $\mathrm{pH}$ solution, was elucidated. $\mathrm{pH}$ is a key factor influencing the oral drug delivery. It is known that $\mathrm{pH}$ is about 1.22.0 in stomach, about 7.0 in small intestine and as high as 8 in the distal part (Shargel and Yu, 2014).

The release of cardanol at $\mathrm{pH} 1$ from compound $\mathrm{f}-\mathrm{HNT}$ reaches a plateau after about $250 \mathrm{~min}$, an initial burst is observed within $200 \mathrm{~min}$ followed by a prolonged release.

Release profiles obtained at $\mathrm{pH} 6$ and $\mathrm{pH} 7.4$ showed a similar behavior than $\mathrm{pH} 1$ but, in both cases, a smallest amount of cardanol was released from the systems.

In order to further study the release behavior of cardanol from $\mathrm{f}$ HNT in different $\mathrm{pH}$ solution, the in vitro release data were fitted to various models to analyze the kinetics and the release mechanism of cardanol.

The experimental data were analyzed using first-order equation: (1) (Gibaldi and Feldman, 1967), double exponential model (DEM) (2) (Wilczak and Keinath, 1993), Higuchi's square root model (3) (Higuchi, 1963) and the Power law (4) (Ritger and Peppas, 1987; Sipemann and Peppas, 2001) to elucidate the release kinetics of cardanol.

The used equations are following listed:

$$
F_{t}=1-e^{-k t}
$$

(a)

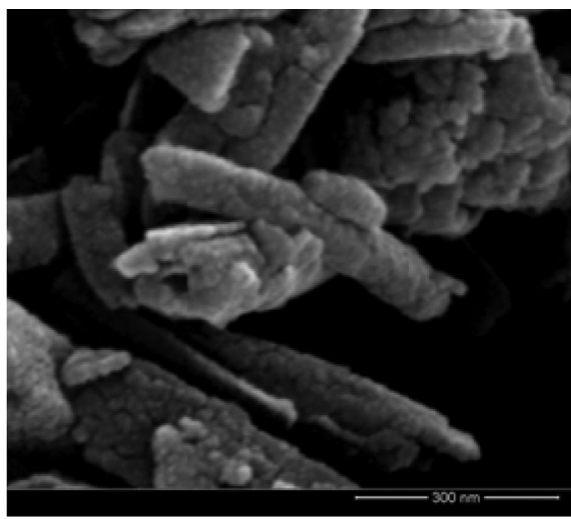

(b)

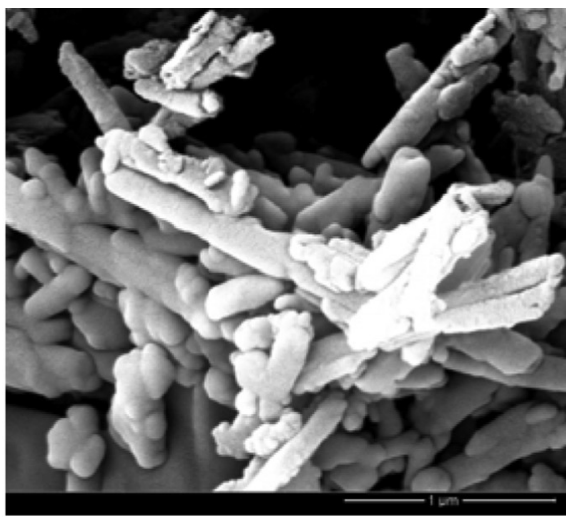

(c)

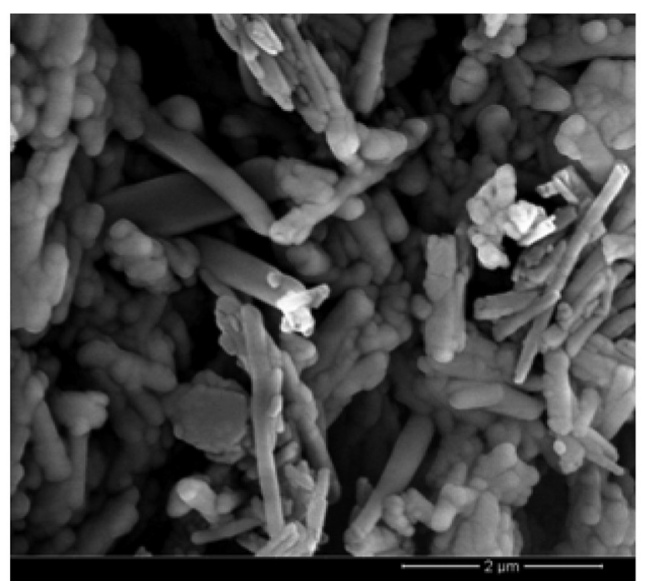

Fig. 8. SEM images of (a and b) f-HNT/Card complex and (c) p-HNT/Card complex. 


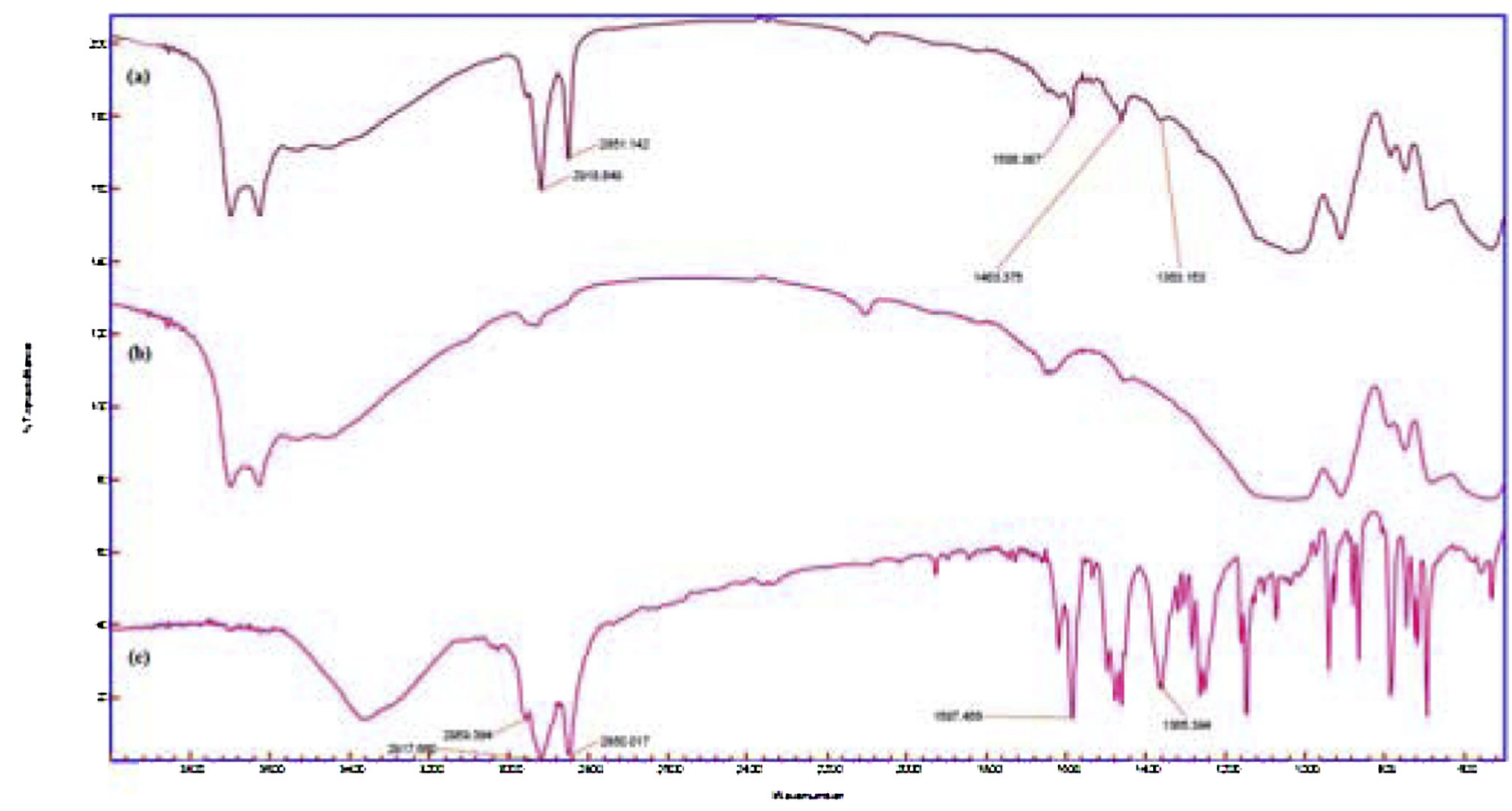

Fig. 9. IR spectra of (a) f-HNT/Card complex; (b) f-HNT and (c) pure cardanol.

(a)

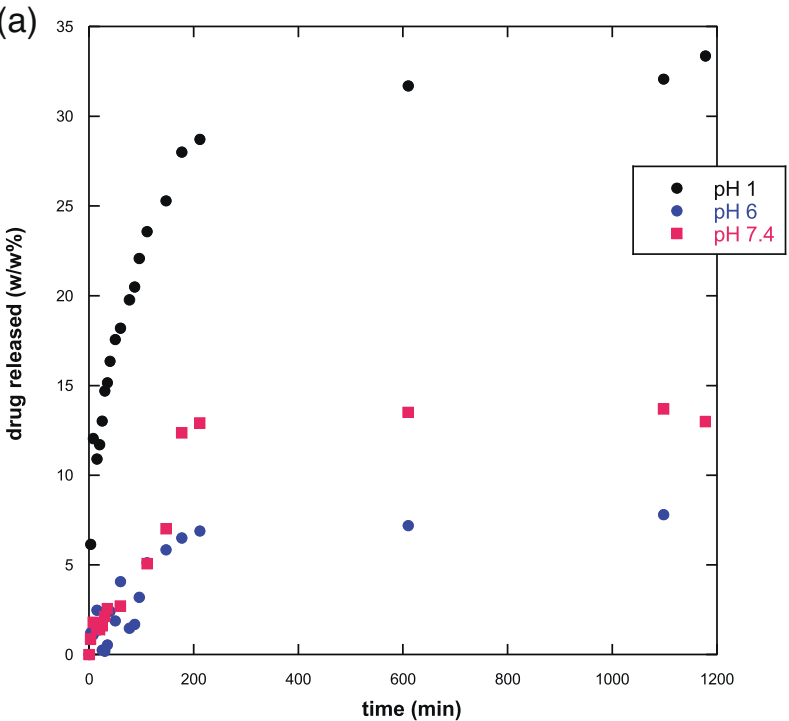

(b)

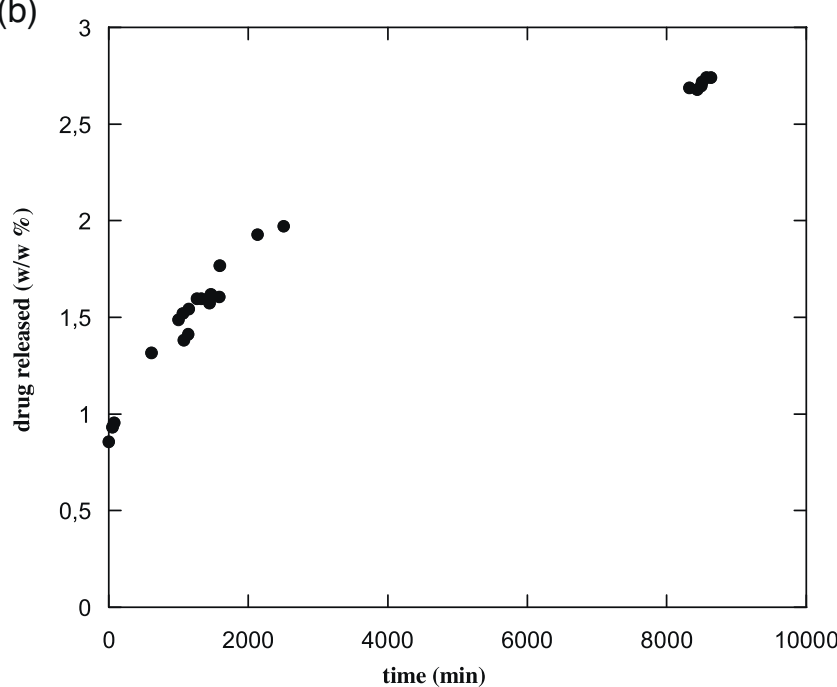

Fig. 10. (a) Variation of release of cardanol from f-HNT with $\mathrm{pH}$ in the release medium. (b) Amount of cardanol released from p-HNT in $0.1 \mathrm{M}$ HCl solution.

Table 1

Kinetic parameters for the release of cardanol from f-HNT in $\mathrm{HCl} 0.1 \mathrm{~N}, \mathrm{pH} 6$ and pH 7 phosphate buffer.

\begin{tabular}{|c|c|c|c|c|c|c|c|c|c|}
\hline \multirow[t]{2}{*}{$\mathrm{pH}$} & \multicolumn{3}{|l|}{ First-order } & \multicolumn{2}{|l|}{ DEM } & \multicolumn{2}{|l|}{ Higuchi } & \multicolumn{2}{|c|}{ Power law } \\
\hline & $k_{\mathrm{d}}\left(\min ^{-1}\right)$ & $R^{2}$ & $\begin{array}{c}k_{\mathrm{d}}^{\prime} \\
\left(\min ^{-1}\right)\end{array}$ & $\begin{array}{c}k_{\mathrm{d}}^{\prime \prime} \\
\left(\mathrm{min}^{-1}\right)\end{array}$ & $R^{2}$ & $\begin{array}{l}k_{\mathrm{d}} \\
\left(\min ^{-1}\right)\end{array}$ & $R^{2}$ & $\begin{array}{l}k_{\mathrm{d}} \\
\left(\min ^{-1}\right)\end{array}$ & $R^{2}$ \\
\hline 1 & 0.0088 & 0.983 & 0.07 & 0.0077 & 0.955 & 1.88 & 0.977 & 7.356 & 0.899 \\
\hline 6 & 0.0015 & 0.977 & 0.0048 & 0.0045 & 0.834 & 0.142 & 0.959 & 0.225 & 0.960 \\
\hline 7.4 & 0.0022 & 0.985 & 0.0035 & 0.0034 & 0.922 & 0.431 & 0.802 & 0.351 & 0.969 \\
\hline
\end{tabular}



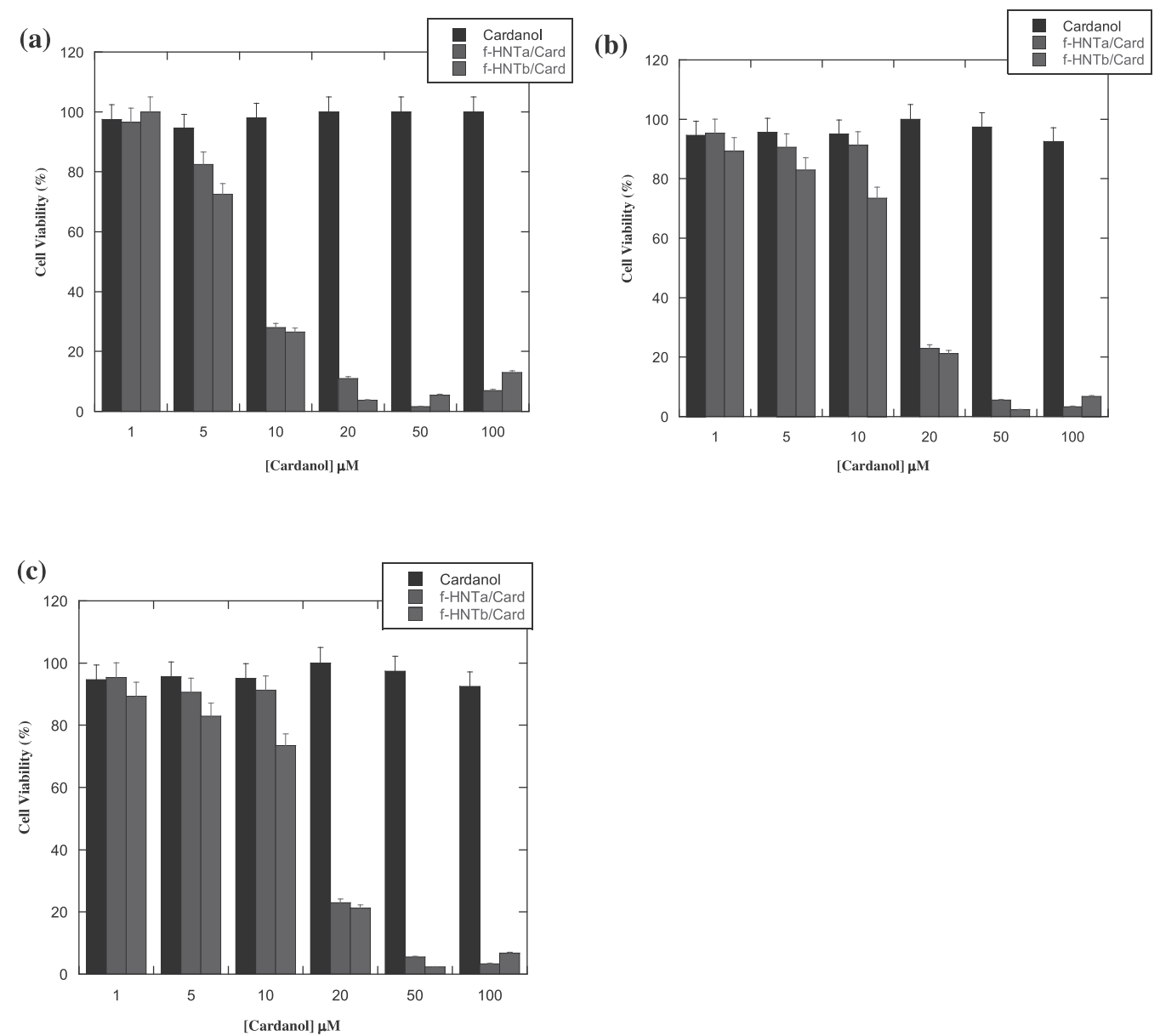

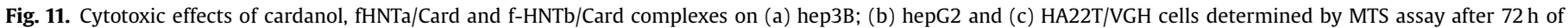
incubation. Values presented are means $\pm \mathrm{SD}, n=3$.

$F_{t}=F^{\prime}{ }_{e}\left(1-e^{-k^{\prime} t}\right)+F^{\prime \prime}{ }_{e}\left(1-e^{-k^{\prime \prime} t}\right)$

$F_{t}=k t^{\frac{1}{2}}$

$F_{t}=k t^{n}$

where $F_{t}$ is the drug release fraction at time $t, k$ is the release constant of the respective equations, $t$ is the release time and $n$ is the characteristic diffusion exponent.

The correlation coefficient $\left(R^{2}\right)$ for Eq. (1) is above 0.97 at different $\mathrm{pH}$ solution and it is higher than the other kinetics equations (Table 1 ), suggesting that the release mode of cardanol follows the first-order kinetics.

Because cardanol is only adsorbed on HNT outer surface, the overall release process is due to only one desorption step.

The same conclusions could be done for the cardanol release from p-HNT (Fig. 10). Also in this case, the release mode of cardanol follows the first-order kinetics $\left(k_{\mathrm{d}}=0.00033 \pm 0.00002 \mathrm{~min}^{-1}\right.$; $R^{2}=0.994$ ).

\subsection{Cell viability}

In order to validate the efficiency of p-HNT/Card and f-HNT/ Card on cell viability we tested a panel of 3 tumor cell lines, namely
HA22T/VGH, Hep3B and HepG2. We performed MTS test in order to verify if the complexes are able to exert a cytotoxic action.

Cell viability was estimated at $72 \mathrm{~h}$ under different cardanol concentrations (in the $1-100 \mu \mathrm{M}$ range). It was observed that cell viability decreases in a concentration and time dependent way.

The effects of Cardanol, f-HNTa/Card and f-HNTb/Card complexes on the relative cell viability of Hep3B, HepG2 and HA22T/ VGH cell lines are shown in Fig. 11.

It is remarkable to note that there was no significant reduction in cell viability following incubation with various concentrations of p-HNT with all types of cells, indicating that the pristine halloysite carriers had no toxic effects on the cells. When the cells were incubated with f-HNT, on the contrary, we observed a little cytotoxicity against the several cell lines (Riela et al., 2014). This is not surprisingly because we have developed a new system with triazole, which is known to possess biological activity.

Free cardanol has no effect on cell viability, probably due to its low solubility in physiological medium, which limits its clinical application.

No cytotoxic effects for the several cell lines in the presence of the complex p-HNT/Curc were observed.

The f-HNTa/Card and f-HNTb/Card complexes show, at each concentration, a significantly higher cytotoxicity than free cardanol and p-HNT/Card. The concentrations of f-HNTa/Card and $\mathrm{f}-\mathrm{HNTb} / \mathrm{Card}$ which caused 50\% inhibition of cell growth are reported in Table 2 for all cell lines.

This increase in cytotoxicity compared with free cardanol and p-HNT/Card complex suggests that the introduction of triazole 
Table 2

$\mathrm{IC}_{50}$ of $\mathrm{f}-\mathrm{HNTa} / \mathrm{Card}$ and $\mathrm{f}-\mathrm{HNTb} /$ Card for the three cell lines.

\begin{tabular}{llr}
\hline Complex & Cell line & $\mathrm{IC}_{50}(\mu \mathrm{M})$ \\
\hline f-HNTa/Card & HA22 T/VGH & $18 \pm 6$ \\
& hep3b & $8 \pm 1$ \\
& hepG2 & $27 \pm 5$ \\
& & \\
fHNTb/Card & HA22 T/VGH & $17 \pm 7$ \\
& hep3b & $7 \pm 3$ \\
& hepG2 & $25 \pm 12$ \\
\hline
\end{tabular}

exerts a synergic effect with cardanol and could improve the permeability of cells in a concentration dependent manner combined with enhanced aqueous solubility of f-HNTa/Card and f-HNTb/Card.

In effect, a cationic surface promotes the interaction between the nanoparticles and the cells, and hence increases the rate and extent of internalization (Shenoy and Amiji, 2005).

The internalization mechanism presumably involves an endocytosis process, whereby f-HNTa-b could be uptaken into the cytosol by endosomes (Zhang et al., 2009).

\section{Conclusions}

We explored the possibility to use halloysite nanotubes as drug delivery system for cardanol that in turn has been revealed a natural active molecule in cancer treatments. The interaction in solution between cardanol and nanotubes was clearly evidenced by HPLC, which endowed to calculate the concentration of free and bound drug to the carrier. The effect of halloysite outer surface functionalization was investigated by covalently linking triazolium salts with substituents of different hydrophobicity. The nanotubes/ cardanol complexes were characterized in the dried solid. The loading efficiency of cardanol onto both pristine nanotubes and modified halloysite was satisfactory. The drug release from the carrier occurs in ca. $6 \mathrm{~h}$ and the released amount as well as the kinetic parameters are strongly influenced by the $\mathrm{pH}$. Cytotoxicity experiments on several cell lines proved that cardanol is a promising anticancer and that the use of chemically modified nanotubes exercises synergic effects likely improving the permeability of cells to cardanol. The paper represents a step forward to the use of halloysite nanotubes in drug delivery.

\section{Author contributions}

The manuscript was written through contributions of all authors. All authors have given approval to the final version of the manuscript.

\section{Acknowledgments}

The work was financially supported by the University of Palermo, PRIN 2010-2011 (prot. 2010329WPF) and FIRB 2012 (prot. RBFR12ETL5). The authors would like to thank Prof. O. Attanasi (University of Urbino) for providing cardanol.

\section{References}

Abdullayev, E., Joshi, A., Wei, W., Zhao, Y., Lvov, Y., 2012. Enlargement of halloysite clay nanotube lumen by selective etching of aluminum oxide. ACS Nano 6 , $7216-7226$

Abdullayev, E., Lvov, Y., 2010. Clay nanotubes for corrosion inhibitor encapsulation: release control with end stoppers. J. Mater Chem. 20, 6681-6687.

Abdullayev, E., Sakakibara, K., Okamoto, K., Wei, W., Ariga, K., Lvov, Y., 2011. Natural tubule clay template synthesis of silver nanorods for antibacterial composite coating. ACS Appl. Mater. Interfaces 3, 4040-4046.

Amin, A.R., Kucuk, O., Khuri, F.R., Shin, D.M., 2009. Perspectives for cancer prevention with natural compounds. J. Clin. Oncol. 27, 2712-2725.
Feng, M., Gao, W., Wang, R., Chen, W., Man, Y.-G., Figg, W.D., Wang, X.X., Dimitrov, S. S., Ho, M.P., 2013. Therapeutically targeting glypican-3 via a conformationspecific single-domain antibody in hepatocellular carcinoma. Natl. Acad. Sci. U. S. A. 110, E1083-E1091.

Florea, A.-M., Büsselberg, D., 2011. Cisplatin as an anti-tumor drug: cellular mechanisms of activity, drug resistance and induced side effects. Cancers 3, 1351-1371.

Gibaldi, M., Feldman, S., 1967. Establishment of sink conditions in dissolution rate determinations. Theoretical considerations and application to nondisintegrating dosage forms. J. Pharm. Sci. 56, 1238-1242.

Gullett, N.P., Ruhul, A., Bayrakatar, S., Pezzuto, J.M., Shin, D.M., Khuri, F.R., Aggarwal, B.B., Surh, Y.J., Kucuk, O., 2010. Cancer prevention with natural compounds. Semin. Oncol. 37, 258-281.

Higuchi, T., 1963. Mechanism of sustained-action medication. Theoretical analysis of rate of release of solid drugs dispersed in solid matrices. J. Pharm. Sci. 52, $1145-1149$.

Horcajada, P., Marquez-Alvarez, C., Ramila, A., Perez-Pariente, J., Vallet-Regi, M., 2006. Controlled release of Ibuprofen from dealuminated faujasites. Solid State Sci. 8, 1459-1465.

Ito, Y., Arai, K., Uchino, K., Iwasaki, K., Shibata, N., Takada, K., 2005. Effect of adsorbents on the absorption of lansoprazole with surfactant. Int. J. Pharm. 289, 69-77.

Izzo, P.T., Dawson, C.R., 1950. Cashew nut shell liquid. VII. The higher olefinic components of cardanol. J. Org. Chem. 15, 707-714.

Jain, S.K., Awasthi, A.M., Jain, N.K., Agrawal, G.P., 2005. Calcium silicate based microspheres of repaglinidefor gastroretentive floating drug delivery: preparation andin vitro characterization. J. Control. Release 107, 300-309.

Joussein, E., Petit, S., Churchman, J., Theng, B., Righi, D., Delvaux, B., 2005. Halloysite clay minerals - a review. Clay Miner. 40, 383-426.

Lvov, Y.M., Shchukin, D.G., Möhwald, H., Price, R.R., 2008. Halloysite clay nanotubes for controlled release of protective agents. ACS Nano 2, 814-820.

Mahata, D., Mandal, S.M., Bharti, R., Gupta, V.K., Mandal, M., Nag, A., Nando, G.B. 2014. Self-assembled cardanol azo derivatives as antifungal agent with chitinbinding ability. Int. J. Biol. Macromol. 69, 5-11.

Massaro, M., Riela, S., Cavallaro, G., Gruttadauria, M., Milioto, S., Noto, R., Lazzara, G. 2014a. Eco-friendly functionalization of natural halloysite clay nanotube with ionic liquids by microwave irradiation for Suzuki coupling reaction. J Organomet. Chem. 749, 410-415.

Massaro, M., Riela, S., Lo Meo, P., Noto, R., Cavallaro, G., Milioto, S., Lazzara, G, 2014b. Functionalized halloysite glycocluster as a new drug delivery system. J. Mater. Chem. B doi:http://dx.doi.org/10.1039/C4TB01272K.

Massaro, M., Riela, S., Lazzara, G., Gruttadauria, M., Milioto, S., Noto, R., 2014c. Green conditions for the Suzuki reaction using microwave irradiation and a new HNTsupported ionic liquid-like phase (HNT-SILLP) catalyst. Appl. Organomet. Chem. 28, 234-238.

Martucci, A., Pasti, L., Marchetti, N., Cavazzini, A., Dondi, F., Alberti, A., 2012. Adsorption of pharmaceuticals from aqueous solutions on synthetic zeolites. Micropor. Mesopor. Mater. 148, 174-183.

Meyskens, F.L., Gerner, E.W., 1999. Development of difluoromethylornithine (DFMO) as a chemoprevention agent. Clin. Cancer Res. 5, 945-951.

Mizushima, Y., Ikoma, T., Tanaka, J., Hoshi, K., Ishihara, T., Ogawa, Y., Ueno, A., 2006. Injectable porous hydroxyapatite microparticles as a new carrier for protein and lipophilic drugs. J. Control. Release 110, 260-265.

Price, R., Gaber, B.P., Lvov, Y., 2001. In-vitro release characteristics of tetracycline $\mathrm{HCl}$, khellin and nicotinamide adenine dineculeotide from halloysite; a cylindrical mineral. J. Microencapsul. 18, 713-722.

Riela, S., Massaro, M., Colletti, C.G., Bommarito, A., Giordano, C., Milioto, S., Noto, R Poma, P., Lazzara, G., 2014. Development and characterization of co-loaded curcumin/triazole-halloysite systems and evaluation of their potential anticancer activity. Int. J. Pharm. 475, 613-623.

Ritger, P.L., Peppas, N.A., 1987. A simple equation for description of solute release I. Fickian and non-Fickian release from non-swellable devices in the form of slabs spheres, cylinders or discs. J. Control. Release 5, 23-36.

Shargel, L., Yu, A., 2014. Applied Biopharmaceutics and Pharmacokinetics. McGraw Hill, New York.

Shchukin, D.G., Sukhorukov, G.B., Price, R.R., Lvov, Y.M., 2005. Halloysite nanotubes as biomimetic nanoreactors. Small 1, 510-513.

Shenoy, D.B., Amiji, M.M., 2005. Poly(ethylene oxide)-modified poly ( $\gamma$-caprolactone) nanoparticles for targeted delivery of tamoxifen in breast cancer. Int. J. Pharm. 293, 261-270.

Sipemann, J., Peppas, N.A., 2001. Modeling of drug release from delivery systems based on hydroxypropyl methylcellulose (HPMC). Adv. Drug Deliv. Rev. 48, 139-157.

Song S.W., Hidajat, K., Kawi, S., 2005. Functionalized SBA-15 materials as carriers for controlled drug delivery: influence of surface properties on matrix-drug interactions. Langmuir 21, 9568-9575.

Streubel, A., Siepmann, J., Bodmeier, R., 2002. Floating microparticles based on low density foam powder. Int. J. Pharm. 241, 279-292.

Suzuki, R., Takizawa, T., Kuwata, Y., Mutoh, M., Ishiguro, N., Utoguchi, N., Shinohara, A. Eriguchi, M., Yanagie, H., Marayuma, K., 2008. Effective anti-tumor activity of oxaliplatin encapsulated in transferrin-PEG-liposome. Int. J. Pharm. 346, $143-150$.

Teerasripreecha, D., Phuwapraisirisan, P., Puthong, S., Kimura, K., Okuyama, M., Mori, H., Kimura, A., Chanchao, C., 2012. In vitro antiproliferative/cytotoxic activity on cancer cell lines of a cardanol and a cardol enriched from Thai Apis mellifera propolis. Complem. Altern. Med. 12, 27-44. 
Tsuda, H., Ohshima, Y., Nomoto, H., Fujita, K., Matsuda, E., Iigo, M., Takasuka, N., Moore, M.A., 2004. Cancer prevention by natural compounds. Drug Metab. Pharmacokinet. 19, 245-263.

Vallet-Regi, M., Ramila, A., del Real, R.P., Perez-Pariente, J., 2001. A new property of MCM-41: crug delivery system. Chem. Mater. 13, 308-311.

Vergaro, V., Abdullayev, E., Lvov, Y.M., Zeitoun, A., Cingolani, R., Rinaldi, R., Leporatti, S., 2010. Cytocompatibility and uptake of halloysite clay nanotubes. Biomacromolecules 11, 820-826.

Wilczak, A., Keinath, T.M., 1993. Kinetics of sorption and desorption of copper(II) and lead(II) an activated carbon. Water Environ. Res. 65, 238-244.
Wilson, T.R., Fridlyand, J., Yan, Y., Penuel, E., Burton, L., Chan, E., Peng, J., Lin, E., Wang, Y., Sosman, J., Ribas, A., Li, J., Moffat, J., Sutherlin, D.P., Koeppen, H., Merchant, M., Neve, R., Settleman, J., 2012. Widespread potential for growth-factor-driven resistance to anticancer kinase inhibitors. Nature 487 505-509.

Yuang, P., Southon, P.D., Liu, Z., Green, M.E.R., Hook, J.M., Antill, S.J., Kepert, C.J., 2008. Functionalization of halloysite clay nanotubes by grafting with $\gamma$-aminopropyltriethoxysilane. J. Phys. Chem. C 112, 15742-15751.

Zhang, S., Li, J., Lykotrafitis, G., Bao, G., Suresh, S., 2009. Size-dependent endocytosis of nanoparticles. Adv. Mater. 21, 419-424. 